\title{
Comparative Response in Growth and Bone Status to Three Dexamethasone Treatment Regimens in Infant Piglets
}

\author{
CHUN-YUAN GUO, WENDY WARD, PAMELA CAIRNS, AND STEPHANIE ATKINSON
}

Department of Pediatrics, McMaster University, Hamilton, Ontario, L8N 3Z5, Canada

\begin{abstract}
The objectives of this study were 1 ) to determine whether a zenith in bone formation (indicated by circulating osteocalcin) existed at night in early life, and 2) to compare the effects of three different dexamethasone (DEX) treatment regimens on bone turnover, bone mineral content, and growth. Three DEX treatment regimens were tested in 8 -d-old piglets ( $n=8$ /group): 1 ) low evening dose of DEX $(0.5 \mathrm{mg} / \mathrm{kg} / \mathrm{d})$ as $70 \%$ in the morning and $30 \%$ in the evening for $10 \mathrm{~d} ; 2)$ tapering course of DEX $(0.5$, 0.3 , and $0.2 \mathrm{mg} / \mathrm{kg} / \mathrm{d}$ ) as $50 \%$ in the morning and $50 \%$ in the evening for $14 \mathrm{~d}$; and 3) constant dose of DEX $(0.5 \mathrm{mg} / \mathrm{kg} / \mathrm{d})$ as $50 \%$ in the morning and $50 \%$ in the evening for $10 \mathrm{~d}$. Oral water placebo groups were tested with the same time courses. At pretreatment, plasma osteocalcin was significantly higher $(p<$ $0.05)$ at 0100 than at 0900 and 1700 . At necropsy, measures for DEX groups were calculated as Z-scores using values from the placebo groups. The low evening DEX dose led to a significantly lower reduction in plasma osteocalcin compared with the tapered and constant dosing regimens $(p<0.05)$. The significant weight
\end{abstract}

\section{ABSTRACT}

reduction in the DEX group occurred at $\mathrm{d} 9$ in the low evening dose regimen but at $\mathrm{d} 7$ in the constant dosing regimen, compared with the placebo group. Bone mineral content Z-score was reduced similarly in all DEX-treated groups across the three dosing regimens. We conclude that a plasma osteocalcin zenith at night exists in early life. A high DEX dose in the morning and low DEX dose in the evening may partially attenuate corticosteroid-induced suppression of bone formation and growth restriction. (Pediatr Res 48: 238-243, 2000)

$\quad$ Abbreviations
BMC, bone mineral content
Cr, creatinine
CV, coefficient of variation
DEX, dexamethasone
NTx, $N$-terminal telopeptide of type I collagen
VLBW, very low birth weight

VLBW infants may develop severely compromised lung function because of their immaturity. The incidence of bronchopulmonary dysplasia in VLBW infants has been reported to be as high as $70 \%$ (1). DEX is prescribed for these infants to improve pulmonary compliance and to facilitate earlier weaning from the ventilator $(2,3)$. However, linear, weight and bone growth can be adversely affected by DEX administration in VLBW infants (4-7). Despite these side effects, DEX continues to be used in treatment of chronic lung disease $(8-10)$. Although both tapered (3-6) and constant (8) dosing regimens are used in clinical practice, it is not known whether they induce similar restrictions in growth and bone development.

The rapidly growing piglet is a good model for human infants (11). From our experience with piglets, monitoring growth for a 2 -wk period $(12,13)$ parallels the changes in

Received November 8, 1999; accepted March 22, 2000.

Correspondence and reprint requests: Dr. Stephanie Atkinson, Department of Pediatrics, McMaster University Medical Center HSC-4V42, 1200 Main Street West, Hamilton, Ontario, L8N 3Z5, Canada.

Supported by the Medical Research Council of Canada, the Hospital for Sick Children Foundation in Toronto, and the Molly Towell Perinatal Research Foundation. weight (4-fold increase) and length (1.2-fold increase) that we observe in VLBW human infants over $8.5 \mathrm{wk}$ or from their birth to term-adjusted age (4). Piglets respond like human infants in the metabolic processing of minerals, and they have been used successfully to measure responses in growth and bone development to alterations in dietary minerals (14), administration of $\operatorname{DEX}(12,13)$, and GH treatment (12).

Corticosteroids adversely alter skeletal metabolism through multiple pathways, such as inhibition of intestinal calcium absorption (13), increased osteoclast-mediated bone resorption (15), direct stimulation of renal excretion of calcium (15), and the direct suppression of bone formation (16). A circadian rhythm in bone formation has been reported in adults and children, with a zenith at night and nadir in the morning (17, 18). Circadian rhythm in bone formation has not been assessed in infants; possibly because of the difficulty of collecting serial blood samples from newborn infants. If a zenith at night in bone formation exists in early life, it would be clinically useful to administer a higher morning dose and a lower evening dose of DEX. Such a low evening dosing regimen may potentially 


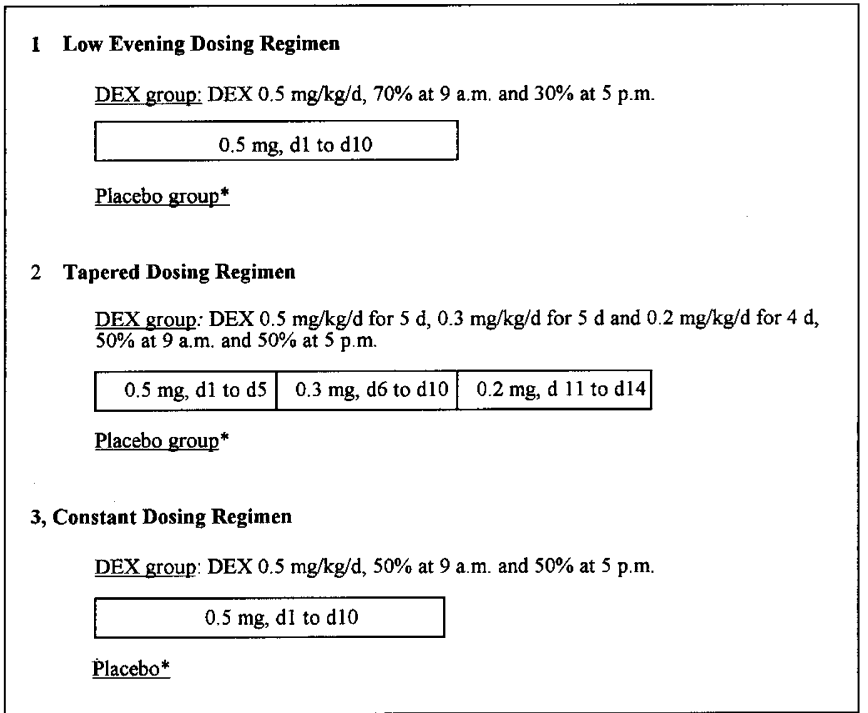

Figure 1. Study design. *Placebo groups were given $0.5 \mathrm{~mL}$ of distilled water twice a day.

attenuate DEX-induced suppression of bone formation at the night zenith.

This study was designed using the infant piglet model with the objectives 1 ) to observe whether a zenith in bone formation exists at night in early life; and 2) to compare the effects of three DEX treatment regimens - low evening/high morning dose, tapered dose, or constant dose - on bone turnover, BMC, and growth.

\section{METHODS}

Animals and care. Forty-eight 5-d-old male Yorkshire piglets were removed from the sow at the Swine Research Facility, Arkell Farms (Guelph, Ontario, Canada) and transported to the McMaster University Central Animal Facility. All procedures were in agreement with the Guide for the Care and Use of Experimental Animals (19) and were approved by the McMaster Animal Research Ethics Board. Piglets were housed in stainless steel metabolic cages under heat lamps that maintained an ambient temperature of $28-30^{\circ} \mathrm{C}$. The piglets were fed an artificial formula that provided energy $(3344 \mathrm{~kJ} / \mathrm{L})$, protein $(40 \mathrm{~g} / \mathrm{L})$, vitamins, and minerals in accordance with the nutrient requirements for growing piglets (13). Warmed formula $(400 \mathrm{~mL} / \mathrm{kg} / \mathrm{d})$ was offered in equal amounts four times per day based on the piglets' fasting morning weight.

Study design. Piglets were adapted to formula and the environment for $3 \mathrm{~d}$ and then were block randomized to DEX (sodium phosphate salt Hexadrol; Orgaon Teknika, Toronto, Canada) or placebo vehicle within low evening dosing, tapered dosing, or constant dosing regimens ( $n=8$ for each group) when they were $8 \mathrm{~d}$ old (Fig. 1). This DEX protocol mimics the dosing regimens used in the management of VLBW infants. DEX and placebo in doses noted in Figure 1 were administered by orogastric gavage technique. At necropsy day, the cumulative dose of DEX was 13.9, 14.0, and $13.9 \mathrm{mg}$, respectively, in low evening, tapered, and constant dosing regimens.

Sampling. Blood was collected at 0900 in a nonfed state on the day before DEX treatment ( $\mathrm{d} 0$ ) as the baseline sample, and at necropsy (d 11 for low evening dose and constant dose regimens and d 15 for tapered dose regimen). In the low evening dose study, baseline blood was also collected at 1700 and 0100 randomly in a subset of piglets (four from the DEX group and four from the placebo group) to assess the zenith of bone formation. Blood was collected in all piglets by a blind stab of the interior jugular at baseline and by a cardiac puncture at end of treatment while the piglets were under light anesthesia (isoflurane gas, Aerrane; Anaquest, Mississauga, Ontario, Canada). Time to recovery after anesthesia was 5 minutes. Urine was collected for $24 \mathrm{~h}$ at baseline and the day before necropsy. Twenty-four-hour urine was collected in dishes placed under the metabolic cages. All blood samples were stored at $-70^{\circ} \mathrm{C}$, and urine samples were stored at $-20^{\circ} \mathrm{C}$, until analyzed. Whole-body BMC was analyzed in the evening before the necropsy day. Body weight was measured daily on a digital scale. Body length was measured at baseline and at necropsy while piglets were anesthetized for blood sampling. Femoral length was measured at necropsy day in excised bone.

Methods of analyses. Plasma osteocalcin (Bone Gla-protein, BGP), used as a bone formation marker, was measured by RIA (DiaSorin Inc, Stillwater, MN, U.S.A.) with purified bovine osteocalcin as standard and tracer and rabbit antiserum to bovine osteocalcin. The intraassay $\mathrm{CV}$ calculated from duplicates was $6.7 \%$. The interassay CV previously reported from our laboratory was $6.1 \%$ (14). Twenty-four-hour urinary NTx, used as a bone resorption marker, was measured by ELISA (Osteomark ${ }^{\circledR}$, NTX Urine, Ostex International, Inc., Seattle, WA, U.S.A.). Triplicate analysis of two piglet samples at three different concentrations demonstrated the linearity of the assay with correlation coefficients of 0.99 , similar to the correlation coefficients reported in human samples by Ostex International Inc. Assay values were standardized to an equivalent amount of bone collagen, and were expressed in nanomoles bone collagen equivalents (BCE) as a ratio to body weight. The intraassay CV calculated from duplicates was $6.6 \%$, and the interassay $\mathrm{CV}$ previously reported from our laboratory was $5.7 \%$ (12). Plasma BGP measured by RIA and urinary NTx measured by ELISA have been proved to be reliable and sensitive in pig samples $(12,13,20,21)$. Plasma cortisol was

Table 1. Characteristics of piglets in different dosing regimens at pretreatment (mean $\pm S D$ )

\begin{tabular}{lcrrr}
\hline & \multicolumn{1}{c}{$\begin{array}{c}\text { Constant } \\
\text { dose }(n=8)\end{array}$} & $\begin{array}{c}\text { Low evening } \\
\text { dose }(n=8)\end{array}$ & \multicolumn{1}{c}{$\begin{array}{c}\text { Tapered dose } \\
(n=8)\end{array}$} & $\begin{array}{c}\text { Controls* } \\
(n=24)\end{array}$ \\
\hline Body weight $(\mathrm{kg})$ & $2.3 \pm 0.2$ & $2.3 \pm 0.3$ & $2.3 \pm 0.3$ & $2.3 \pm 0.3$ \\
Body length $(\mathrm{cm})$ & $42.9 \pm 1.5$ & $42.1 \pm 1.4$ & $41.1 \pm 1.5$ & $42.2 \pm 1.5$ \\
Plasma BGP (ng/ml) & $21.4 \pm 2.9$ & $29.9 \pm 6.3$ & $26.1 \pm 4.9$ & $25.4 \pm 5.2$ \\
Urinary NTx/weight (nM BCE/g) & not available & $2.6 \pm 0.7$ & $3.0 \pm 0.8$ & $2.8 \pm 0.9$ \\
\hline
\end{tabular}

\footnotetext{
* From all three placebo groups in the three dosing regimens; one-way ANOVA, $p>0.05$ for all measurements.
} 
Table 2. Daily energy intakes (KJ/d, mean $\pm S D$ )

\begin{tabular}{ccccc}
\hline Days & $\begin{array}{c}\text { Controls* } \\
(n=24)\end{array}$ & $\begin{array}{c}\text { Tapered dose } \\
(n=8)\end{array}$ & $\begin{array}{c}\text { Constant dose } \\
(n=8)\end{array}$ & $\begin{array}{c}\text { Low evening dose } \\
(n=8)\end{array}$ \\
\hline 1 & $3157 \pm 294$ & $3237 \pm 401$ & $3103 \pm 321$ & $3224 \pm 361$ \\
6 & $4321 \pm 401$ & $4013 \pm 603$ & $3839 \pm 401$ & $3946 \pm 495$ \\
11 & $5979 \pm 775$ & $5049 \pm 936$ & $4601 \pm 361$ & $4976 \pm 361$ \\
\hline
\end{tabular}

* From all three placebo groups in the three dosing regimens.

measured by RIA (DiaSorin Inc) at the necropsy day in the piglets treated with constant and low evening dosing regimens and their corresponding controls. The intraassay $\mathrm{CV}$ calculated from duplicates in our laboratory was $6.1 \%$, and the interassay $\mathrm{CV}$ evaluated from the kit manufacturer was $9.0 \%$. The minimum detectable values for plasma osteocalcin, cortisol, and urinary NTx were $0.2 \mathrm{ng} / \mathrm{mL}, 21.0 \mathrm{ng} / \mathrm{dL}$, and $20.0 \mathrm{nmol} \mathrm{BCE \text {, }}$ respectively. Whole-body BMC was measured by dual-energy x-ray absorptiometry (DXA, Hologic QDR 1000W; Hologic Inc, Waltham, MA, U.S.A.) using the pediatric whole-body software program (V5.63P, Hologic Inc). Piglets were placed on the scan field in a spread-eagle position. Placement $\mathrm{CV}$ for the whole-body BMC was $1.2 \%$ (22).

Statistical analysis. During treatment and at necropsy day, piglets treated with placebo for $10 \mathrm{~d}$ in the constant and low evening dosing regimens were combined as one control group $(\mathrm{n}=16)$, whereas piglets treated with placebo for $14 \mathrm{~d}$ were used as controls $(n=8)$ for piglets treated with a tapered course of DEX for $14 \mathrm{~d}$. Measures for DEX groups were calculated as Z-scores at the necropsy day. The Z-scores for constant and low evening dosing regimens were derived from those control piglets treated with placebo for $10 \mathrm{~d}(n=16)$, whereas the Z-scores for tapered dosing regimen were derived from its own corresponding control piglets, which were treated with placebo for $14 \mathrm{~d}(n=8)$. Repeated measures ANOVA with Bonferroni correction was used to assess the plasma osteocalcin at 0900, 1700, and 0100. All other statistical comparisons were performed using one-way ANOVA with Bonferroni correction.

\section{RESULTS}

At baseline, there were no differences in body weight, length, or biochemical markers of bone turnover among the three placebo groups. The baseline measurements also did not differ between DEX groups and controls, which represented the combined placebo groups in the three studies $(n=24$; Table 1). The energy intake for all piglets is reported in Table 2 . Plasma osteocalcin measured at 0100 was $45.1 \pm 7.5 \mathrm{ng} / \mathrm{mL}$ (mean $\pm \mathrm{SD}$ ), which is significantly higher than that measured at $0900(25.4 \pm 6.1 \mathrm{ng} / \mathrm{mL})$ and at $1700(27.8 \pm 7.4 \mathrm{ng} / \mathrm{mL}$; Fig. 2).

Body weights in the three DEX-treated groups were all significantly lower than those in placebo groups at the necropsy day (Fig. 3). A significant body weight difference between the DEX group and placebo group occurred at $\mathrm{d} 7$ in the constant dosing regimen but at $\mathrm{d} 9$ in the low evening dosing regimen (Fig. 3).

At necropsy day, plasma cortisol in control piglets was $2701 \pm 894 \mathrm{ng} / \mathrm{dL}$ (mean $\pm \mathrm{SD}$ ) which is significantly higher than cortisol in piglets treated with constant dosing $(919 \pm 443$ $\mathrm{ng} / \mathrm{dL})$ and low evening dosing $(1107 \pm 528 \mathrm{ng} / \mathrm{dL})$ regimens

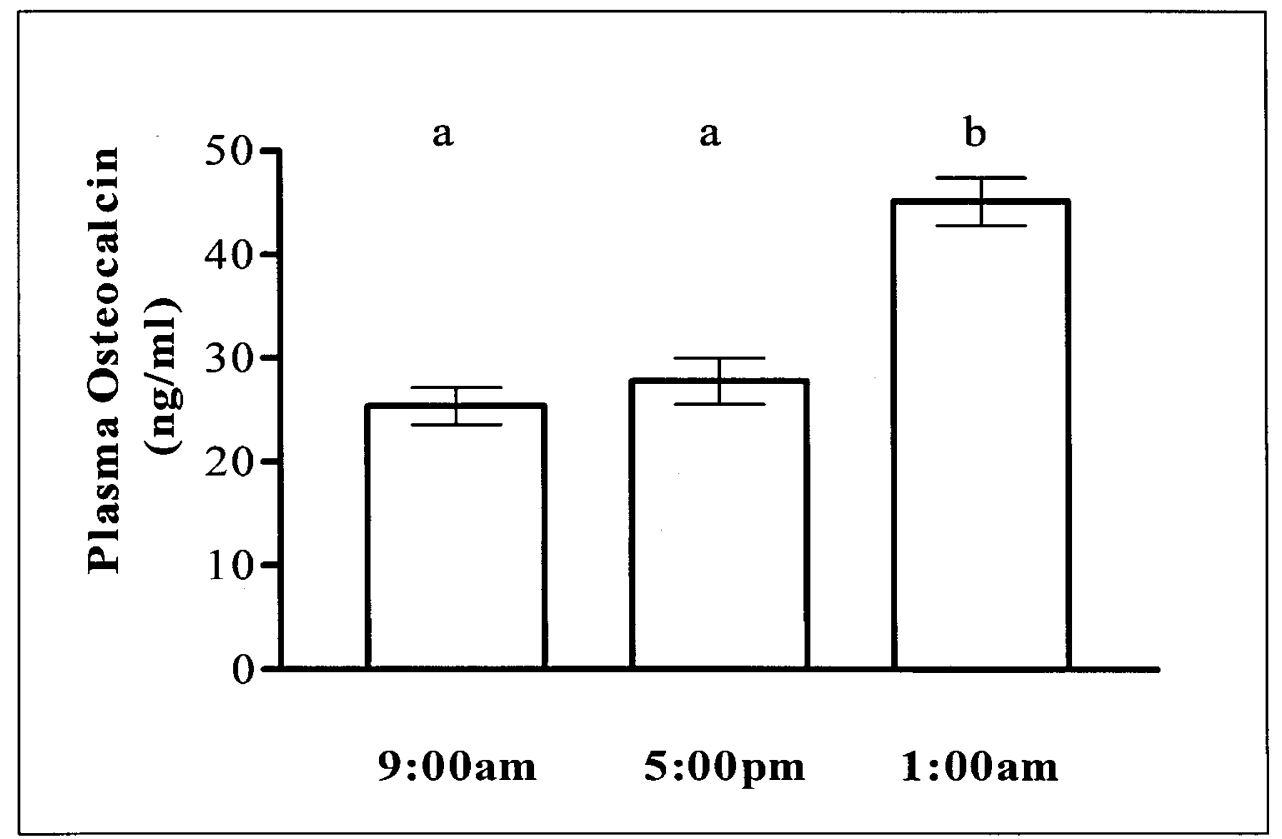

Figure 2. Plasma osteocalcin at 0900,1700 , and 0100 at baseline. The bars represent means, and the whiskers represent SEM. a $v s$ b indicates a significant difference, $p<0.05$. 


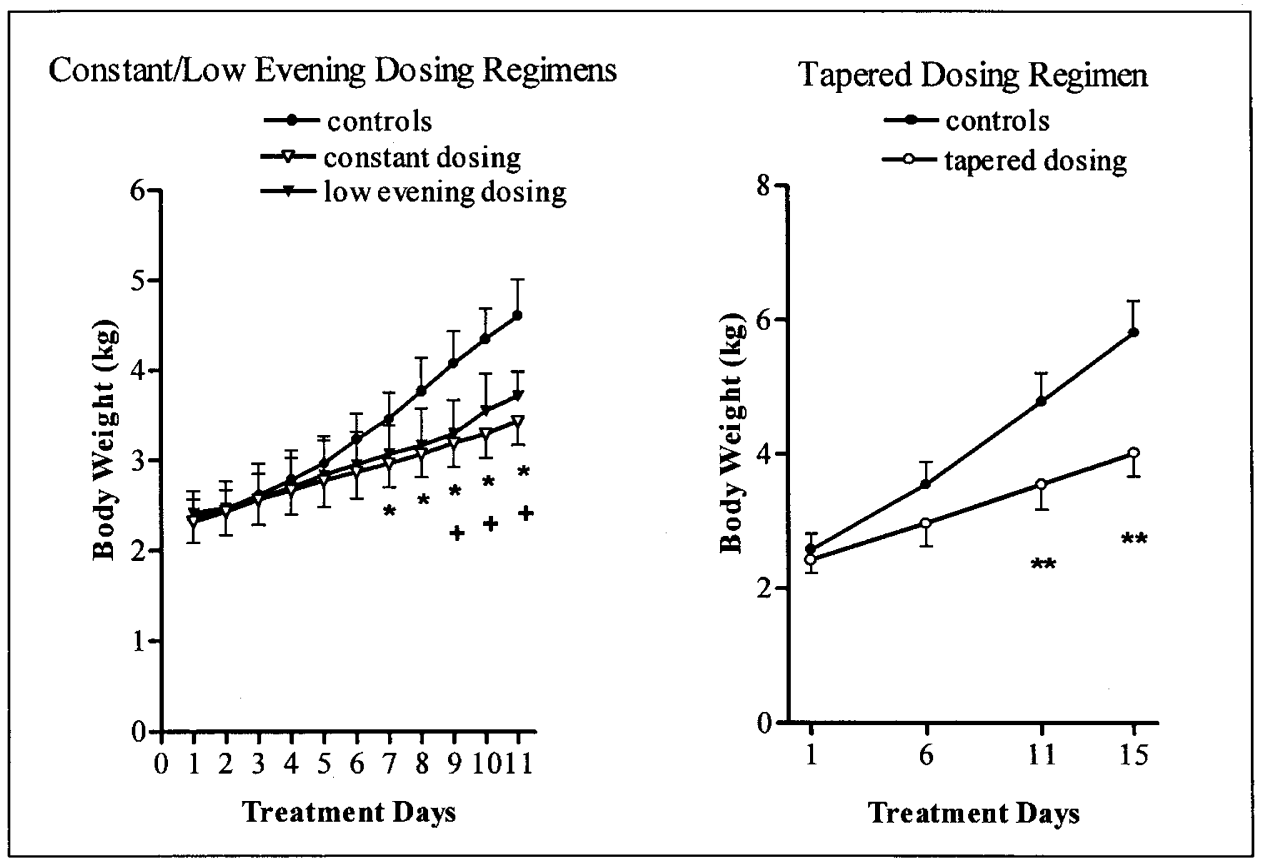

Figure 3. Body weight in low evening and constant dosing regimens (Left) and in tapered dosing regimen (Right) during treatment. The control group for the constant and low evening dosing regimens was a combination of their corresponding placebo groups treated with placebo for $10 \mathrm{~d}(n=16)$. The piglets treated with placebo for $14 \mathrm{~d}$ were used as controls $(n=8)$ for piglets treated with a tapered course of DEX for $14 \mathrm{~d}$. The lines represent means, and the whiskers represent SEM. *Constant dose $v s$ control, $p<0.05 ;$ + Low evening dose $v s$ control, $p<0.05$; **Tapered dose $v s$ control, $p<0.05$.

$(p<0.05)$. Plasma cortisol did not differ between the two DEX treatment groups (Fig. 4). BMC, body weight and length, femoral length, plasma osteocalcin, and urinary NTx/weight in the three DEX-treated groups were all significantly lower than those in corresponding placebo groups at necropsy day. When the three dosing regimens were compared, Z-scores for BMC, body weight and length, urinary NTx/weight, and femoral length did not differ among the three DEX groups (Fig. 5). However, the low evening dosing regimen attenuated the reduction in plasma osteocalcin significantly compared with the tapered dosing and constant dosing regimens (Fig. 5).

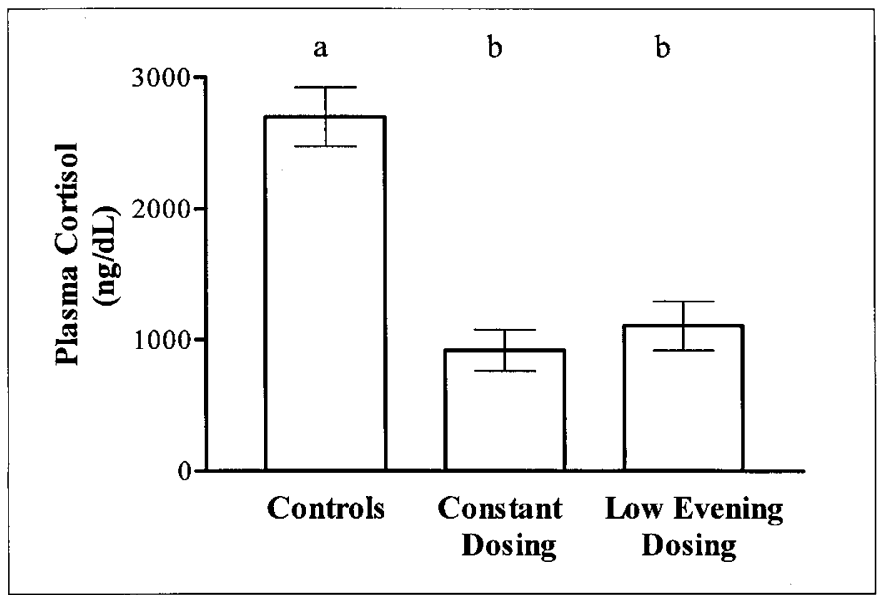

Figure 4. Plasma cortisol in piglets treated with constant dose of DEX $(n=$ $8)$, low evening dose of DEX $(n=8)$, and placebo controls $(n=16)$ at necropsy day. The control group was a combination of the two placebo groups in the constant and low evening dosing regimens $(n=16)$. The format is the same as in Figure 2.

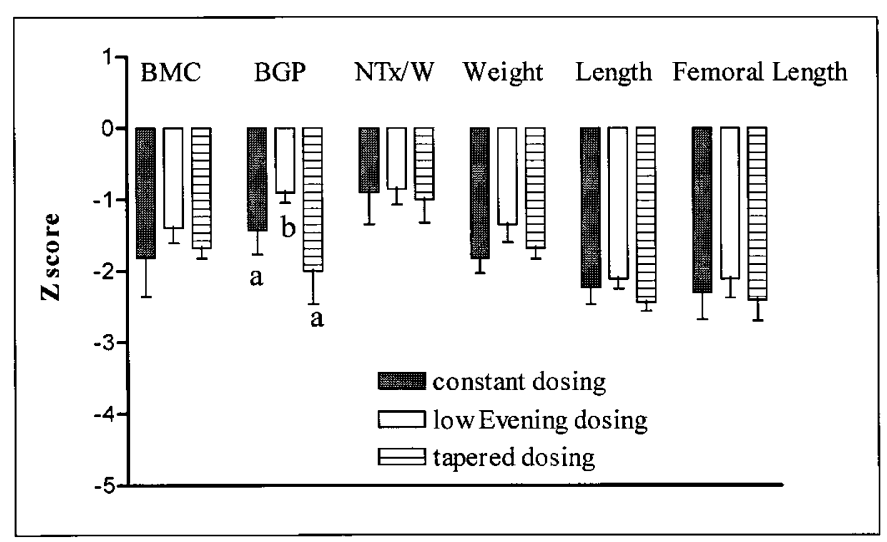

Figure 5. Z-scores for BMC, plasma osteocalcin (BGP), urinary NTx/body weight, body weight, body length, and femoral length at the end of treatment for each of the dosing regimens. The format is the same as in Figure 2.

\section{DISCUSSION}

Osteocalcin, a sensitive bone formation marker, was reported previously in adults and children to have a zenith at night and nadir in the morning $(17,18)$. In the present study, a similar nocturnal zenith in plasma osteocalcin was observed in infant piglets. The factors controlling this rhythm are unclear. In children and adults, a circadian rhythm in bone formation paralleled that observed for circulating cortisol $(17,23)$ and PTH (24) but was relatively unaffected by age, sex hormone status, sex (25), or bed rest (26). A longitudinal study measuring human infant salivary cortisol, reflecting the free fraction of plasma cortisol, demonstrated that a diurnal rhythm for cortisol occurs as early as $2 \mathrm{wk}$ of age (27). Therefore, plasma cortisol may also regulate the circadian rhythm in bone formation during infancy. 
In the present study, we demonstrated that endogenous cortisol was inhibited during DEX treatment, which is consistent with a previous study in human infants (28). Thus, the exogenous DEX treatment, rather than the endogenous cortisol, may be the major regulator for circulating osteocalcin. By using a low evening dosing regimen with high DEX dose $(70 \%)$ in the morning and low DEX dose (30\%) in the evening, we demonstrated that corticosteroid-induced suppression of bone formation as determined by plasma osteocalcin and growth as determined by body weight were partially attenuated. Thus, the low evening dose of DEX may allow for a more normal physiologic milieu of growth factors to be operational during the night.

The Z-scores for body weight did not differ among the three treatment regimens at the necropsy day as determined by one-way ANOVA. Interpretation of the body weight may be limited by the relatively small sample size and the multiple comparisons. Application of a Bonferroni adjustment for multiple comparisons suggests that only $p<0.0167$ should be considered statistically significant. For this reason, the $p$ value for body weight can really only suggest and identify trends in the data that ideally should be confirmed in a larger study. Inasmuch as the tapered dosing of DEX did not attenuate the negative effects of the steroids on bone formation and growth, the cumulative dose of DEX may be the key factor causing the side effects, especially when given in evenly divided doses in the morning and evening.

Urinary NTx has been expressed as a ratio to urinary Cr. Urinary biochemical bone resorption markers adjusted by urinary $\mathrm{Cr}$ were either normal (29-32) or increased $(33,34)$. Because urinary $\mathrm{Cr}$ excretion is primarily a function of muscle mass, and protein synthesis and lean muscle mass are substantially reduced in subjects taking corticosteroids (35), it is possible that much of the apparent increase in bone resorption marker reported in previous studies $(33,34)$ is a function of reduced $\mathrm{Cr}$ excretion (36). We used body weight to standardize urinary NTx in the present study. Urinary NTx/weight was lower in all DEX groups compared with respective placebo groups at the end of treatment but did not differ among the three dosing regimens as determined by Z-scores. The lack of effect of dosing regimens on bone resorption may relate to a lesser effect of the corticosteroid on bone resorption than on bone formation (36). It is believed the inhibition of osteoblastogenesis and promotion of apoptosis of osteoblasts and osteocytes are key pathogenetic mechanisms of corticosteroidinduced osteoporosis (37). In addition, the methods available for evaluating bone resorption have been less reliable than those for bone formation because most of the biochemical markers of bone resorption are measured in urine (16). A sensitive biochemical marker of bone resorption measured in blood, cross-linked C-telopeptide of Type I collagen (CrossLaps or CTx (38), was reduced in infant piglets treated with DEX in our previous study (39).

We conclude that a plasma osteocalcin zenith exists at night in early life. High DEX dose in the morning and low DEX dose in the evening may partially attenuate corticosteroid-induced suppression of bone formation and growth. This physiologic approach to steroid therapy should be studied in VLBW infants to determine whether the desired therapeutic efficacy can be achieved while at the same time minimizing the negative effects on growth and bone turnover.

Acknowledgment. The authors thank Nicole Campbell and Christopher McAllister for their assistance with piglet care.

\section{REFERENCES}

1. Northway Jr WH 1990 Bronchopulmonary dysplasia: then and now. Arch Dis Child 65:1076-1081

2. Kazzi NJ, Brans YW, Poland RL 1990 Dexamethasone effects on the hospital course of infants with bronchopulmonary dysplasia who are dependent on artificial ventilation. Pediatrics 86:722-727

3. Cummings JJ, D'Eugenio DB, Gross SJ 1989 A controlled trial of dexamethasone in preterm infants at high risk for bronchopulmonary dysplasia. N Engl J Med 320:1505-1510

4. Weiler HA, Paes B, Shah JK, Atkinson SA 1997 Longitudinal assessment of growth and bone mineral accretion in prematurely born infants treated for chronic lung disease with dexamethasone. Early Hum Dev 47:271-286

5. Brownlee KG, Ng PC, Henderson MJ, Smith M, Green JH, Dear PRF 1992 Catabolic effect of dexamethasone in the preterm baby. Arch Dis Child 61:1-4

6. Gibson AT, Pearse RG, Wales JKH 1993 Growth retardation after dexamethasone administration: assessment by knemometry. Arch Dis Child 69:505-509

7. Ward WE, Atkinson SA, Donovan SM, Paes B 1999 Bone metabolism and circulating IGF-I and IGFBPs in dexamethasone-treated preterm infants. Early Hum Dev $56: 127-141$

8. Collaborative Dexamethasone Trial Group 1991 Dexamethasone therapy in neonatal chronic lung disease: an international placebo-controlled trial. Pediatrics 88:421-427

9. Moriette G, Mikaeloff Y, Jarreau PH, Desfrere L 1999 Corticosteroid and chronic lung disease in extremely immature infants: a dilemma. Pediatr Pulmonol 18(suppl):209-211

10. Bhuta T, Ohlsson A 1998 Systematic review and meta-analysis of early postnatal dexamethasone for prevention of chronic lung disease. Arch Dis Child 79:F26-F33

11. Miller ER, Ullrey DE 1987 The pig as a model for human nutrition. Annu Rev Nutr 7:361-382

12. Ward WE, Donovan SM, Atkinson SA 1998 Dexamethasone-induced abnormalities in growth and bone metabolism in piglets are partially attenuated by growth hormone with no synergistic effect of insulin-like growth factor-I. Pediatr Res 44:215-221

13. Weiler HA, Wang Z, Atkinson SA 1995 Dexamethasone treatment impairs calcium regulation and reduces bone mineralization in infant pigs. Am J Clin Nutr 61:805811

14. Atkinson SA, Shah JK, Webber CE, Gibson IL, Gibson RS 1993 A multi-element isotopic tracer assessment of true fractional absorption of minerals from formula with additives of calcium, phosphorus, zinc, copper and iron in young piglets. J Nutr 123:1586-1593

15. Khosla S, Melton III LJ 1995 Corticosteroid-induced osteoporosis. In: Riggs BL, Melton III LJ (eds) Osteoporosis, Etiology, Diagnosis and Management, 2 Ed. Lippincott-Raven, Philadelphia, pp 185-189

16. Eastell R 1995 Management of corticosteroid-induced osteoporosis. J Intern Med 237:439-447

17. Saggese G, Baroncelli GI, Bertelloni S, Cinquanta L, Dinero G 1994 Twenty-fourhour osteocalcin, carboxyterminal propeptide of type I procollagen, and aminoterminal propeptide of type III procollagen rhythms in normal and growth-retarded children. Pediatr Res 35:409-415

18. Eastell R, Simmons PA, Colwell A, Assiri AMA, Burritt MF, Russell G, Riggs BL 1992 Nyctohemeral changes in bone turnover assessed by serum bone Gla-protein concentration and urinary deoxypyridinoline excretion: effects of growth and aging. Clin Sci 83:375-382

19. Canadian National Research Council 1984 Guide for the care and use of experimental animals. Vol 2. Ottawa, Canada: Institute of Laboratory Animal Resources of The National Research Council

20. Eklou-Kalonji E, Zerath E, Colin C, Lacroix C, Holy X, Denis I, Pointillart A 1999 Calcium-regulating hormones, bone mineral content, breaking load and trabecular remodeling are altered in growing pigs fed calcium-deficient diets. J Nutr 129:188 193

21. Pointillart A, Colin C, Lacroix HC, Gueguen L 1995 Mineral bioavailability and bone mineral contents in pigs given calcium carbonate postprandially. Bone 17:357-362

22. Brunton JA, Weiler HA, Atkinson SA 1997 Improvement in the accuracy of dual energy x-ray absorptiometry for whole body and regional analysis of body composition: validation using piglets and methodological considerations in infants. Pediatr Res 41:1-7

23. Nielsen HK, Brixen K, Kassem M, Charles P, Mosekilde L 1994 Inhibition of the morning cortisol peak abolishes the expected morning decrease in serum osteocalcin in normal males: evidence of a controlling effect of serum cortisol on the circadian rhythm in serum osteocalcin. J Clin Endocrinol Metab 74:1410-1414

24. Nielsen HK, Laurberg P, Brixen K, Mosekilde L 1991 Relations between diurnal variations in serum osteocalcin, cortisol, parathyroid hormone, and ionized calcium in normal individuals. Acta Endocrinol 124:391-398 
25. Nielsen HK, Brixen K, Mosekilde L 1990 Diurnal rhythm and 24-hour integrated concentrations of serum osteocalcin in normal: influence on age, sex, season and smoking habits. Calcif Tissue Int 47:284-290

26. Nielsen HK, Brixen K, Kassem M, Christensen SE, Mosekilde L 1991 Diurnal rhythm in serum osteocalcin: relation with sleep, growth hormone, and $\mathrm{PTH}(1-84)$. Calcif Tissue Int 49:373-377

27. Santiago LB, Jorge SM, Coreira AC 1996 Longitudinal evaluation of the development of salivary cortisol circadian rhythm in infancy. Clin Endocrinol 44:157-161

28. Ng PC, Wong GW, Lam CW, Lee CH, Fok TF, Wong MY, Wong W, Chan DC 1997 Pituitary-adrenal suppression and recovery in preterm very low birth weight infants after dexamethasone treatment for bronchopulmonary dysplasia. J Clin Endocrino Metab 82:2429-2432

29. Boulet LP, Giguere MC, Milot J, Brown J 1994 Effects of long-term use of high-dose inhaled steroids on bone density and calcium metabolism. J Allergy Clin Immunol 94:796-803

30. Nielsen HK, Thomsen K, Eriksen EF, Charles P, Storm T, Mosekilde L 1988 The effects of high-dose glucocorticoid administration on serum bone gamma carboxyglutamic acid-containing protein, serum alkaline phosphatase and vitamin D metabolites in normal subjects. Bone Min 4:105-113

31. Jennings BH, Andersson KE, Johannsson SA 1991 Assessment of systemic effects of inhaled glucocorticosteroids; comparison of the effects of inhaled budesonide and oral prednisolone on adrenal function and markers of bone turnover. Eur J Clin Pharmaco 40:77-82
32. Packe GE, Douglas JG, McDonald AF, Robins SP, Reid DM 1992 Bone density in asthmatic patients taking high dose inhaled beclomethasone dipropionate and intermittent systemic corticosteroids. Thorax 47:414-417

33. Hodsman AB, Toogood JH, Jennings B, Fraher LJ, Baskerville IC 1991 Differential effects of inhaled budesonide and oral prednisolone on serum osteocalcin. J Clin Endocrinol Metab 72:530-540

34. Ali NJ, Capewell S, Ward MJ 1991 Bone turnover during high dose inhaled corticosteroids treatment. Thorax 46:160-164

35. Ward WE, Atkinson SA 1999 Growth hormone and insulin-like growth factor-I therapy promote protein deposition and growth in dexamethasone-treated piglets. J Pediatr Gastroenterol Nutr 28:404-410

36. Reid IR 1998 Glucocorticoid effects on bone. [editorial] J Clin Endocrinol Metab $83: 1860-1862$

37. Manolagas SC, Weinstein RS 1999 New developments in the pathogenesis and treatment of steroid-induced osteoporosis. J Bone Min Res 14:1061-1066

38. Bonde M, Garnero P, Fledelius C 1997 Measurement of bone degradation products in serum using antibodies reactive with an isomerized form of an 8 amino acid sequence of the C-telopeptide of type I collagen. J Bone Min Res 12:1028-1034

39. Guo CY, Weiler H, Atkinson SA 1998 Intact parathyroid hormone levels are elevated in infant piglets receiving oral chronic glucocorticoids for 2 weeks. Clin Invest Med (suppl):S35; (abstr \#079) 